\title{
$\beta$-Catenin-Dependent Wnt Signaling in C. elegans: Teaching an Old Dog a New Trick
}

\author{
Belinda M. Jackson ${ }^{1}$ and David M. Eisenmann ${ }^{2}$ \\ ${ }^{1}$ Department of Medicine, Uniformed Services University of the Health Sciences, Bethesda, Maryland 20814 \\ ${ }^{2}$ Department of Biological Sciences, University of Maryland Baltimore County, Baltimore, Maryland 21250 \\ Correspondence: eisenman@umbc.edu
}

\begin{abstract}
Wnt signaling is an evolutionarily ancient pathway used to regulate many events during metazoan development. Genetic results from Caenorhabditis elegans more than a dozen years ago suggested that Wnt signaling in this nematode worm might be different than in vertebrates and Drosophila: the worm had a small number of Wnts, too many $\beta$-catenins, and some Wnt pathway components functioned in an opposite manner than in other species. Work over the ensuing years has clarified that $C$. elegans does possess a canonical Wnt $/ \beta$ catenin signaling pathway similar to that in other metazoans, but that the majority of Wnt signaling in this species may proceed via a variant $\mathrm{Wnt} / \beta$-catenin signaling pathway that uses some new components (mitogen-activated protein kinase signaling enzymes), and in which some conserved pathway components ( $\beta$-catenin, T-cell factor [TCF]) are used in new and interesting ways. This review summarizes our current understanding of the canonical and novel TCF $/ \beta$-catenin-dependent signaling pathways in $C$. elegans.
\end{abstract}

W nts are secreted glycoproteins that function as extracellular signals in a wide group of metazoans, including cnidarians, nematodes, insects, and vertebrates. This evolutionary conservation suggests that cellular signaling mechanisms functioning in response to Wnts were part of the "developmental toolkit" in place at least 500 million years ago in the common ancestor to modern metazoans (Guder et al. 2006). Signaling regulated by Wnt ligand binding plays an important and often essential role in an astounding number of processes during invertebrate and vertebrate development, as well as functioning in the maintenance of adult stem cell populations in vertebrates and Drosophila (reviewed in Clevers 2006; Cadigan and Peifer
2009; MacDonald et al. 2009). In the nematode Caenorhabditis elegans, Wnt signaling is necessary for many events during both embryonic and larval development, and regulates many processes including cell migration, cell polarity, fate specification, axon guidance, synaptogenesis, and stem cell-like renewal (see Eisenmann 2005; Mizumoto and Sawa 2007b; Van Hoffelen and Herman 2008). Intriguingly, although C. elegans uses a Wnt/ $\beta$-catenin or "canonical" signaling pathway similar to that in other metazoans, it also has a second, novel Wnt signaling pathway that uses additional $\beta$-catenins to effect transcriptional up-regulation of target genes by a mechanism distinct from that in the common Wnt pathway (Mizumoto and Sawa 2007b;

Editors: Roel Nusse, Xi He, and Renee van Amerongen

Additional Perspectives on Wnt Signaling available at www.cshperspectives.org

Copyright (C) 2012 Cold Spring Harbor Laboratory Press; all rights reserved; doi: 10.1101/cshperspect.a007948

Cite this article as Cold Spring Harb Perspect Biol 2012;4:a007948 
Phillips and Kimble 2009). Here we summarize our current understanding of these two C. elegans signaling pathways and the ways they are similar to, and diverge from, Wnt signaling pathways in other species. Although recent work has extended our knowledge of Wnt signaling to other nematode species (Zheng et al. 2005; Rudel et al. 2008; Tian et al. 2008; Lin et al. 2009; Owraghi et al. 2010; Seetharaman et al. 2010; Penigault and Felix 2011a; Wang and Sommer 2011), in this review we will concern ourselves with a survey of Wnt signaling in the established model system C. elegans.

\section{THE CONSERVED METAZOAN WNT/ $\beta$-CATENIN SIGNALING PATHWAY}

The best-characterized signaling pathways acting downstream from Wnts in vertebrates and Drosophila are the $\mathrm{Wnt} / \beta$-catenin (i.e., canonical) pathway (MacDonald et al. 2009) and the $\beta$-catenin-independent Wnt/PCP (planar cell polarity) pathway (Axelrod 2009). As the vast majority of Wnt signaling during C. elegans development involves $\beta$-catenin-dependent signaling, in this review we will consider only the Wnt/ $\beta$-catenin signaling pathway elucidated from vertebrate and Drosophila studies (Fig. 1; pathway function reviewed in Cadigan and Peifer 2009; MacDonald et al. 2009).

The main downstream effector of this pathway is a heterodimeric factor composed of the transcription activator $\beta$-catenin and a member of the T-cell factor/lymphoid enhancer factor (TCF/LEF) family of DNA-binding proteins. In the absence of ligand, the TCF/LEF protein is bound at target genes, where it interacts with transcriptional repressor proteins to keep gene expression low (Fig. 1A). Meanwhile, any $\beta$-catenin not located in the cadherin/catenin cell adhesion complex at the plasma membrane is acted on by the "destruction complex," which contains the core scaffolding components adenomatous polyposis coli protein (APC) and Axin and the kinases glycogen synthase kinase $3 \beta$ (GSK3 $\beta$ ) and casein kinase $1 \alpha(\mathrm{CK} 1 \alpha)$. The destruction complex phosphorylates $\beta$-catenin at conserved amino-terminal sites, leading to its ubiquitination and degradation by the proteasome.
Activation of the Wnt $/ \beta$-catenin pathway is initiated when lipid-modified, secreted Wnt ligand binds to a coreceptor consisting of a member of the seven-transmembrane Frizzled receptor family and one of the single-transmembrane low-density lipoprotein receptor-related proteins, LRP5 or LRP6 (Fig. 1B). Ligand binding leads to phosphorylation of the LRP intracellular domain, the recruitment of Axin to the coreceptor, and the inactivation of the destruction complex. Hypophosphorylated cytoplasmic $\beta$ catenin is not degraded, and it translocates into the nucleus, where it heterodimerizes with TCF/ LEF proteins to activate expression of Wnt-responsive target genes.

\section{WNT PATHWAY COMPONENTS IN C. elegans}

The C. elegans genome contains a complement of core Wnt pathway components similar to those in flies and vertebrates, with some interesting differences (see Table 1) (Ruvkun and Hobert 1998; Eisenmann 2005; Hardin and King 2008).

Table 1. C. elegans Wnt pathway components

\begin{tabular}{|c|c|}
\hline Component & C. elegans homolog \\
\hline Porcupine & MOM-1 \\
\hline Wntless & MIG-14 \\
\hline $\begin{array}{l}\text { Retromer } \\
\text { complex }\end{array}$ & VPS-26, VPS-29, VPS-35, others \\
\hline Wnt & $\begin{array}{l}\text { EGL-20, LIN-44, MOM-2, CWN-1, } \\
\text { CWN-2 }\end{array}$ \\
\hline SFRP & SFRP-1 \\
\hline Frizzled & LIN-17, MOM-5, MIG-1, CFZ-2 \\
\hline LRP5/6 & $? ?$ \\
\hline Ryk/Derailed & LIN-18 \\
\hline Ror & CAM-1 \\
\hline Dsh & MIG-5, DSH-1, DSH-2 \\
\hline GSK3 $\beta$ & GSK-3 \\
\hline CK1 & KIN-19 \\
\hline Axin & PRY-1, AXL-1 \\
\hline APC & APR-1 \\
\hline $\begin{array}{l}\beta-\operatorname{TrCP} / \mathrm{F}- \\
\text { box protein }\end{array}$ & LIN-23, others \\
\hline$\beta$-catenin & HMP-2, BAR-1, SYS-1, WRM-1 \\
\hline TCF & POP-1 \\
\hline Groucho/TLE & UNC-37 \\
\hline
\end{tabular}


A
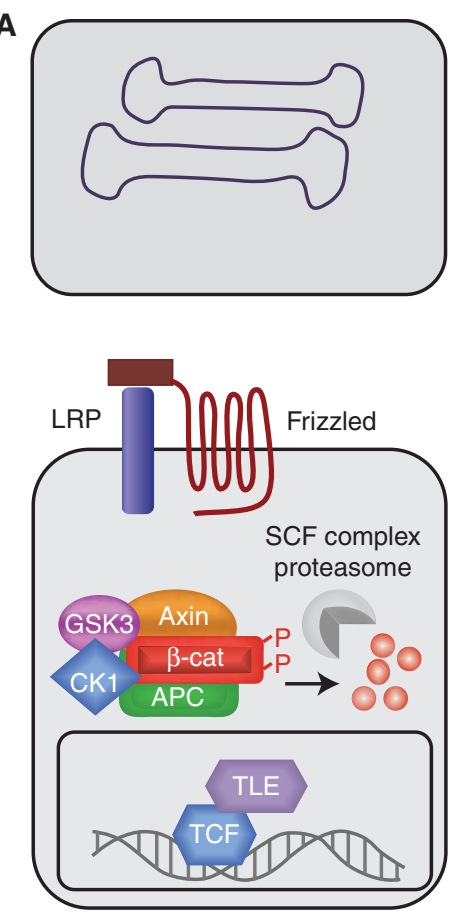

B

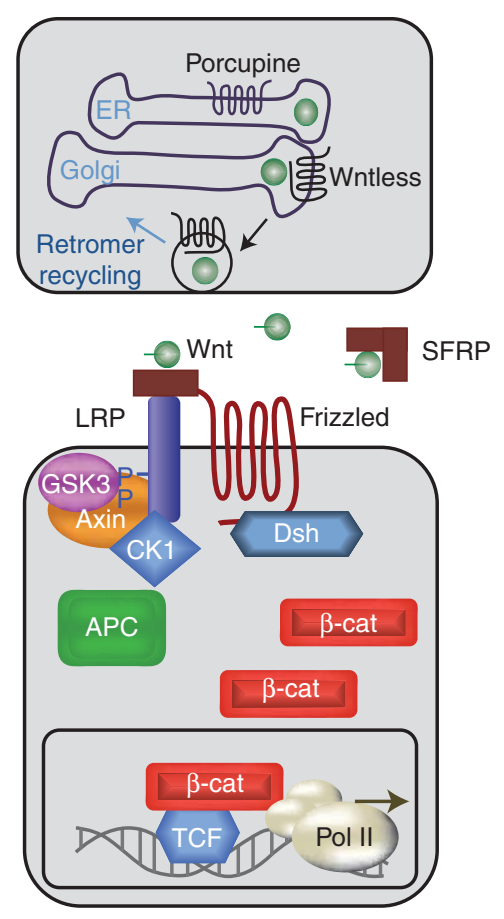

Figure 1. The conserved Wnt/ $\beta$-catenin-dependent signaling pathway. Wnt-sending cells are shown above, Wnt-receiving cells below. (A) In the absence of signal, the destruction complex (including Axin, APC, GSK3 $\beta$, and $\mathrm{CK} 1 \alpha$ ) phosphorylates $\beta$-catenin, targeting it for ubiquitination and destruction by the proteasome. The transcription factor TCF interacts with repressors (including transducing-like enhancers [TLE]) to keep target gene expression low. (B) After processing in the sending cell, some secreted Wnt binds to a Frizzled/LRP coreceptor, which leads to phosphorylation of the intracellular domain of LRP, inactivation of the destruction complex, and stabilization of $\beta$-catenin. After nuclear translocation $\beta$-catenin binds to TCF at Wnt target genes and up-regulates their expression. Some secreted Wnt ligand is sequestered by extracellular inhibitors such as SFRPs.

\section{Wnt Ligands and Inhibitors: Reduced Complexity and Redundancy}

The C. elegans genome contains only five genes encoding Wnt ligands: lin-44, egl-20, mom-2, $c w n-1$, and $c w n-2$ (Shackleford et al. 1993; Herman et al. 1995; Rocheleau et al. 1997; Thorpe et al. 1997; Maloof et al. 1999), a lower number than in other animals. It may have once been assumed this small number was due to some "lower" evolutionary status of nematodes, but genome sequencing of diverse animal species now suggests that the early metazoan common ancestor had a large complement of Wnt genes and that nematode lineages have lost many of these genes (Guder et al. 2006; van Amerongen and Nusse 2009; Janssen et al. 2010; Pang et al.
2010). Surprisingly, only one of the C. elegans Wnts, MOM-2, appears to play a major role during embryogenesis: $\sim 70 \%$ of mom- 2 zygotic mutant animals die during embryogenesis, whereas $<5 \%$ of lin-44; cwn-1; cwn-2 or lin44; cwn-1; egl-20 mutants display embryonic lethality (Thorpe et al. 1997; Gleason et al. 2006). This result is surprising given the apparent reiterated use of Wnt signaling in a large number of asymmetric cell divisions during embryonic development (Park and Priess 2003; Huang et al. 2007). However, both $c w n-1$ and $c w n-2$ mutations enhance the mom-2 lethal phenotype, and the $c w n-1 ; c w n-2 ;$ mom-2 triple mutant shows $100 \%$ lethality, indicating that there is some functional redundancy of Wnts in embryonic development (Gleason et al. 2006). 
B.M. Jackson and D.M. Eisenmann

All five Wnts are also expressed during larval life in discrete locations along the anteriorposterior axis: The Wnts LIN-44, EGL-20, and $\mathrm{CWN}-1$ are expressed in a nested pattern in the posterior, whereas CWN-2 is expressed in more anterior cells (Fig. 2) (Herman et al. 1995; Whangbo and Kenyon 1999; Coudreuse et al. 2006; Gleason et al. 2006; Pan et al. 2006; Kennerdell et al. 2009; Song et al. 2010; Harterink et al. 2011; Yamamoto et al. 2011). Wnts function in several developmental processes along the anterior-posterior axis during larval development, functioning in cell-fate specification, neuronal migration, and neuronal cell polarity (Eisenmann 2005). For several of these larval Wnt-dependent processes, the Wnt genes also display functional redundancy, such that strong phenotypes are only apparent when multiple Wnt genes are mutated (Zinovyeva and Forrester 2005; Gleason et al. 2006; Hilliard and Bargmann 2006; Pan et al. 2006; Prasad and Clark 2006; Green et al. 2008; Yamamoto et al. 2011). This indicates that while in some C. elegans processes, distinct Wnt and Wnt receptor pairings may be used; in other processes, the identity of individual Wnts may not be as important as the reception of a threshold amount of Wnt signal. This redundancy may provide a mechanism for developmental robustness in these processes.
This nested pattern of Wnt expression in the larva (which is set up in the late embryo [Harterink et al. 2011]) is intriguing because Wnt signaling is known to regulate the expression of three C. elegans Hox genes along the larval anterior-posterior axis. It has been proposed that Wnt signaling may have been used as an ancestral axis specification mechanism with patterning by Hox genes elaborated on top of this more ancestral mechanism (Guder et al. 2006; Ryan and Baxevanis 2007; Martin and Kimelman 2009; Petersen and Reddien 2009; Niehrs 2010). Further experiments will need to be performed to determine if specific Hox gene expression along the axis in C. elegans is patterned by the anteriorposterior Wnt gradient.

C. elegans expresses homologs of the Porcupine (MOM-1) and Wntless (MIG-14) proteins, which are required for modification and secretion of Wnts (Rocheleau et al. 1997; Banziger et al. 2006), and of the retromer complex, which acts in the recycling of Wntless in Wnt-sending cells (Belenkaya et al. 2008; Pan et al. 2008; Yang et al. 2008). Mutations affecting the C. elegans genes encoding Porcupine, Wntless, and retromer complex proteins lead to phenotypes in several processes that are consistent with a reduction in Wnt signaling (Rocheleau et al. 1997; Thorpe et al. 1997; Nishiwaki 1999; Eisenmann

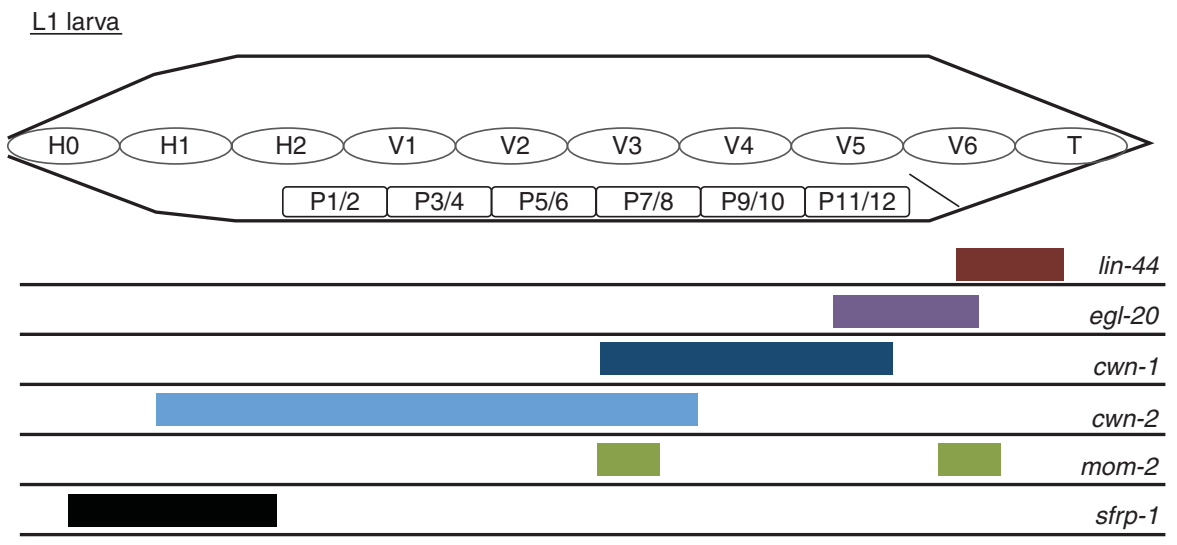

Figure 2. Expression of C. elegans Wnt ligands and a Wnt inhibitor along the anterior-posterior axis. (Top) Diagram of a newly hatched L1 larva; anterior is to the left, dorsal is up. The lateral hypodermal seam cells ( $\mathrm{H} 0-$ $\mathrm{H} 2, \mathrm{~V} 1-\mathrm{V} 6, \mathrm{~T})$ and the ventral hypodermal cells $(\mathrm{P} 1 / 2-\mathrm{P} 11 / 12)$ on the left side are shown. (Bottom) Domains of transcript accumulation along the anterior-posterior axis for each of the five Wnt genes and the Wnt inhibitor $s f r p-1$ at this time in development. (Data from Harterink et al. 2011.) 
and Kim 2000; Coudreuse et al. 2006; Prasad and Clark 2006; Pan et al. 2008; Yang et al. 2008).

In vertebrates a number of secreted Wnt inhibitors are known, which function to modulate response to Wnts (MacDonald et al. 2009). Until recently there was no strong genetic or genome sequence evidence for the presence of such factors in C. elegans, and the only known inhibitor of Wnt ligands was the receptor CAM1 (see below). Recently, a single gene encoding a secreted Frizzled-related protein (SFRP-1) has been identified and shown to be expressed in anterior regions of the worm early in larval development (Fig. 2) (Harterink et al. 2011). In $s f r p-1$ null mutants (which are viable), several neurons show overmigration phenotypes in which they migrate farther into the anterior than in wild type, and reduction of function of Wntless, the retromer complex, or Wnts themselves can suppress these phenotypes (e.g., Fig. $3 \mathrm{E}, \mathrm{F})$. These data suggest that this single secreted Wnt inhibitor likely diffuses from the anterior to bind Wnt ligands and sharpen the Wnt anterior-posterior gradient that controls these processes.

\section{Wnt Receptors: No Coreceptor?}

C. elegans has four genes encoding Frizzled receptors, lin-17, mom-5, mig-1, and cfz-2 (Sawa et al. 1996; Rocheleau et al. 1997; Ruvkun and Hobert 1998; Zhao et al. 2003), and a single Ryk/ Derailed receptor homolog encoded by lin-18 (Inoue et al. 2004), which appear to function

\section{A}

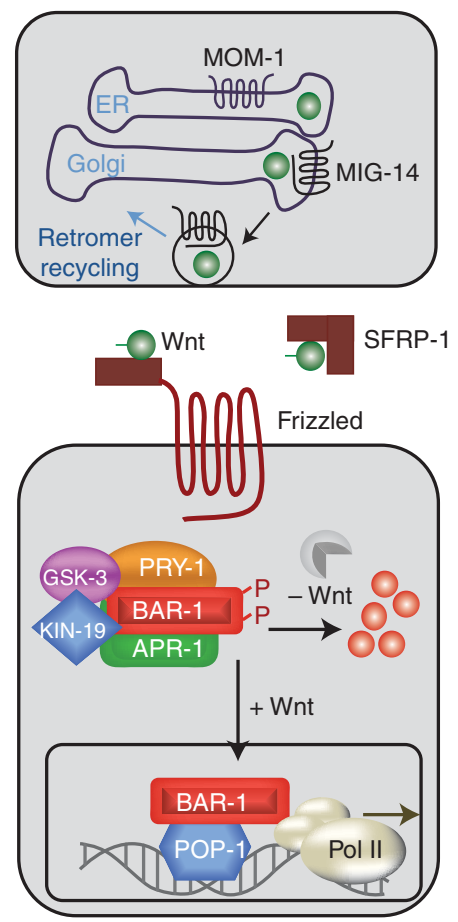

B

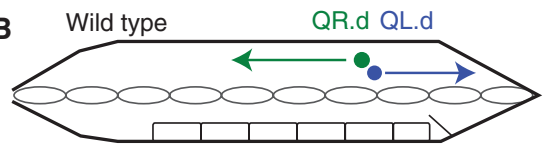

C $\quad m i g-14$, mig-1, vps-35, cam-1(gf), egl-20, lin-17, mig-5, bar-1, pop-1, mab-5

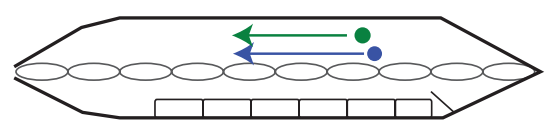

D $\quad$ pry-1, mab-5(gf), HS::sfrp-1

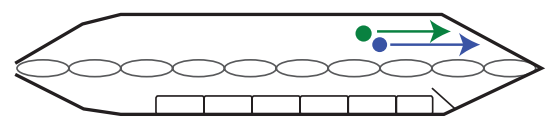

E $\quad s f r p-1$

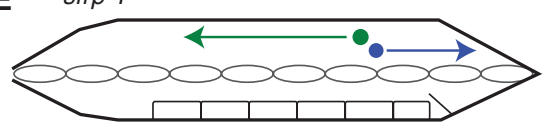

F $\quad$ mig-14 sfrp-1, cwn-1 sfrp-1, cwn-2 sfrp-2

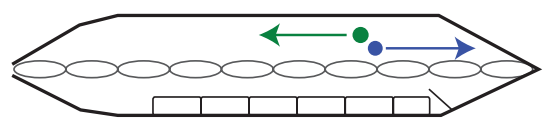

Figure 3. The C. elegans Wnt/BAR-1 canonical (WBC) signaling pathway. $(A)$ The canonical Wnt signaling pathway in C. elegans that uses the $\beta$-catenin BAR-1. Components are drawn similar to those in Figure 1 , with C. elegans protein names given. $(B-F)$ Diagrams show an L1 larval stage animal as in Figure 2. The direction of migration of the descendants of the QR (on the right side) and QL (on the left side) neuroblasts are shown in wild type $(B)$ and various mutant animals $(C-F)$. cam-1 $(g f)$ refers to extra copies of the wild-type cam-1 gene; $m a b-5(g f)$ indicates a mutation causing ectopic expression of mab-5; HS::sfrp-1 indicates expression of sfrp-1 from the heat shock promoter. 
as Wnt receptors. As with the Wnt ligands, for some processes the receptors display genetic redundancy such that Wnt reduction-of-function phenotypes are only seen when multiple genes are mutated (Gleason et al. 2006; Pan et al. 2006; Green et al. 2008; Zinovyeva et al. 2008).

One of the most curious differences between Wnt pathway function in C. elegans and other species is the lack of evidence for a required LRP family coreceptor. Although there are several low-density lipoprotein receptor-related proteins encoded in the worm genome with the domain architecture found in LRP5/6 and Arrow, none have been identified as functioning in a Wnt-mediated process in forward genetic screens, or by directed testing via RNA interference (RNAi) (D Eisenmann, unpubl.). This negative result must be tempered by the caveats of possible functional redundancy and embryonic lethality for genetic analysis, and the apparent rapid divergence of worm homolog sequences in the case of genomic analysis. However, should it hold true that the Wnt binding in C. elegans uses a single receptor, this would raise interesting questions about the mechanism of pathway activation in this species, given the role of the LRP cytoplasmic domain in pathway activation in other species.

In addition to the five receptors mentioned above, the cam-1 gene encodes a Ror tyrosine kinase receptor that functions as a negative Wnt ligand "sink" in several postembryonic processes; only the extracellular cysteine-rich domain is necessary for this activity (Kim and Forrester 2003; Forrester et al. 2004; Green et al. $2007,2008)$. Recent results, however, suggest it may also function in a positive manner as a Wnt receptor in some processes (Hayashi et al. 2009; Kennerdell et al. 2009; Song et al. 2010; Yamamoto et al. 2011).

\section{Disheveled}

The worm genome encodes three Disheveled family members, MIG-5, DSH-1, and DSH-2, which function positively in Wnt signaling and which display genetic redundancy in several cases (Ruvkun and Hobert 1998; Walston et al. 2004; Eisenmann 2005; King et al. 2009).
Destruction Complex: Both Negative and Positive Roles in Wnt Signaling

Genes encoding the core $\beta$-catenin destruction complex components CK1 $\alpha$ (kin-19) (Peters et al. 1999), GSK3 $\beta$ ( $g s k-3$ ) (Schlesinger et al. 1999), Axin (pry-1 and axl-1) (Maloof et al. 1999; Korswagen et al. 2002; Oosterveen et al. 2007), and APC (apr-1) (Rocheleau et al. 1997) are found in C. elegans. In the case of Axin and APC, the encoded proteins are fairly diverged from family members in other species, with several conserved domains absent. In the case of Axin, this low-level homology led to an initial declaration that the C. elegans genome did not encode an Axin homolog (Ruvkun and Hobert 1998). A newly discovered second C. elegans Axin homolog, AXL-1, is even less conserved than PRY-1, yet appears to be a functional Axin protein (Oosterveen et al. 2007). Interestingly, the function of apr-1, gsk-3, and kin-19 appear to differ from process to process, acting positively in some cases (Rocheleau et al. 1997; Peters et al. 1999; Schlesinger et al. 1999). The early observation that the APC homolog APR- 1 acts positively in the Wnt signaling pathway in the P2/EMS asymmetric cell division (see below) led to the idea that Wnt signaling in worms did not proceed via the canonical pathway (Han 1997). However, it is now clear that all of the destruction complex components do function as negative regulators of a canonical worm Wnt pathway in at least one process, vulval cell-fate specification (Gleason et al. 2002, 2006). The observation that the same proteins can function in opposite ways in different Wnt processes raises interesting questions about their substrates and function in those cases in which they act in a positive manner.

\section{$\beta$-Catenins: The More the Merrier}

Unique among sequenced metazoan genomes, C. elegans has four genes encoding $\beta$-catenins, bar-1, hmp-2, sys-1, and wrm-1; all but wrm-1 were identified in forward genetic screens (Rocheleau et al. 1997; Costa et al. 1998; Eisenmann et al. 1998; Kidd et al. 2005). All four encoded proteins are more poorly conserved with $\beta$ catenins from other species than is commonly observed (Phillips and Kimble 2009); HMP-2 
shows the highest identity to human $\beta$-catenin at $\sim 30 \%$. BAR-1, with slightly less identity, is the family member with most of the hallmarks of a stereotypical $\beta$-catenin: 12 Armadillo repeats, transcription activation domains, amino-terminal TCF-binding domain, conserved GSK-3 and CK1 phosphorylation sites in the amino terminus (Eisenmann et al. 1998; Natarajan et al. 2001), and an interaction with a ubiquitin ligase complex that regulates its ubiquitination and accumulation (Dreier et al. 2005). The last C. elegans $\beta$-catenin identified, SYS-1, is only $10 \%$ identical to human $\beta$-catenin, and was predicted to have only three Armadillo repeats, but was suggested to be a bona fide $\beta$ catenin based on genetic data (Siegfried et al. 2004; Kidd et al. 2005). Amazingly, the crystal structure of SYS-1 shows a protein with $12 \mathrm{Ar}$ madillo repeats and a structure very similar to that of vertebrate $\beta$-catenin (Liu et al. 2008). This example shows the strength of the genetic approach in model systems for identification of novel Wnt pathway components and regulators, and again illustrates the danger of relying solely on genome sequence analysis to identify homologous proteins.

One factor that may explain the lower conservation in the nematode $\beta$-catenins is that the dual functions of $\beta$-catenin in Wnt signaling and cell adhesion have been segregated among the four worm proteins. BAR-1 and SYS-1 interact with the TCF family member POP-1 as coactivators of gene expression in two different C. elegans Wnt pathways (Korswagen et al. 2000; Natarajan et al. 2001; Kidd et al. 2005). WRM-1 functions in a variant Wnt signaling pathway with SYS-1 and has acquired the novel function of regulation of TCF nuclear localization (described below). HMP-2 is the only protein with clear function in cell adhesion in a cadherin/ catenin complex (Costa et al. 1998; Korswagen et al. 2000; Natarajan et al. 2001); however, recent work suggests it may also regulate Wnt signaling indirectly (Putzke and Rothman 2010; Sumiyoshi et al. 2011). Thus, by having to maintain only one of the several functions of $\beta$-catenin in other species, $C$. elegans $\beta$-catenin proteins may have been more free to diverge in sequence after gene duplication events occurred.

\section{TCF: There Can Be Only One}

In contrast to vertebrates, the $C$. elegans genome encodes only one TCF/LEF homolog, POP-1 (Lin et al. 1995), which appears to function in all Wnt-mediated processes in the worm, except those that do not involve a transcriptional response (e.g., mitotic spindle rotation) (Eisenmann 2005). Like other TCF proteins, POP-1 has an amino-terminal catenin-binding domain through which it interacts with $\beta$-catenins BAR1 and SYS-1, and an HMG box DNA-binding domain (Korswagen et al. 2000; Natarajan et al. 2001; Kidd et al. 2005). It also possesses an extended carboxy-terminal tail (E tail) similar to that in alternatively spliced isoforms of human TCF1 and TCF4, which functions in auxiliary DNA-binding and protein-protein interactions (Atcha et al. 2003, 2007). Recent work suggests that this carboxy-terminal tail in POP-1 mediates the interaction with the $\beta$-catenin WRM-1 and results in phosphorylation of POP-1 and its nuclear export (Yang et al. 2011) (see below). As with other TCFs, POP-1 is known to function in both the repression of target genes in unsignaled cells and the up-regulation of gene expression upon pathway activation (Owraghi et al. 2010). One curious difference between POP-1 and other TCF family members is its DNA-binding site preference. Several in vitro and in vivo analyses of TCF family members indicate a preference for the core DNA site CTTTGWW (Arce et al. 2006; Hatzis et al. 2008; MacDonald et al. 2009). Although few bona fide POP-1 targets are known in C. elegans, it is clear that POP-1 also binds to sites with a $\mathrm{T}$ instead of a $\mathrm{C}$ nucleotide in the first position (e.g., TTTTGAT in ceh-13 and psa-3 [Streit et al. 2002; Arata et al. 2006] and TTTTGAA in ceh-22 [Lam et al. 2006]). Based on the structure of LEF-1 bound to DNA, POP-1 differs from other TCF family members in amino acid sequence where contact is made at the first nucleotide of the core site (Love et al. 1995). Specifically, POP-1 has a glutamine residue where glutamic acid is found in other TCF family members. However, the substitution of these residues between TCF and POP-1 has no obvious effect on DNA-binding affinity (K Thompson and D Eisenmann, unpubl.). It is currently 
B.M. Jackson and D.M. Eisenmann

unclear what the structural basis for the more promiscuous DNA-binding preference of POP1 is, or if other TCF family members may have a similar specificity.

\section{TWO $\beta$-CATENIN-DEPENDENT WNT SIGNALING PATHWAYS IN C. elegans}

The majority of Wnt-mediated events in $C$. elegans development use one of two signaling pathways. However unlike the two major Wnt pathways in vertebrates, the Wnt/ $\beta$-catenindependent pathway and the Wnt/PCP pathway, both of the C. elegans pathways involve transcriptional regulation of target genes via a $\beta$-catenin/TCF complex (Eisenmann 2005; Phillips and Kimble 2009). One pathway functions mechanistically similarly to the evolutionarily ancient Wnt/ $\beta$-catenin-dependent (canonical) pathway characterized in vertebrates and Drosophila (Figs. 1 and 3). The other pathway, which appears to play a more widespread role in C. elegans development, may be a nematode-specific variation on the canonical Wnt signaling pathway theme (Fig. 4).

\section{THE WNT/BAR-1 CANONICAL (WBC) PATHWAY: OLD DOG}

As mentioned above, homologs of most Wnt/ $\beta$ catenin-dependent pathway components have been identified in C. elegans (Table 1), and genetic and molecular analysis indicates that in several Wnt-mediated processes these proteins function in a manner similar to their vertebrate and fly counterparts (Eisenmann 2005). In all of these processes, the $\beta$-catenin BAR- 1 is uniquely used, and for this reason we term this pathway the Wnt/BAR-1 canonical (WBC) pathway (Fig. 3A). The C. elegans WBC pathway uses all of the positively acting core components of a canonical Wnt pathway (Wnt, Fz, Dsh, $\beta$-catenin, and TCF) except for LRP, and the homologs of the $\beta$-catenin destruction complex components (PRY-1/Axin, GSK-3/GSK3 $\beta$, APR-1/ $\mathrm{APC}$, and KIN-19/CK1 $\alpha$ ) function as negative regulators of this pathway (Eisenmann 2005; Gleason et al. 2006). For example, in pry-1/ Axin mutants, several Wnt-responsive Hox genes (lin-39, mab-1, and egl-5) are expressed outside their normal domains and mutant animals display phenotypes consistent with over- or ectopic activation of the Wnt pathway (Harris et al. 1996; Eisenmann et al. 1998; Maloof et al. 1999; Gleason et al. 2002, 2006; Howard and Sundaram 2002; Korswagen et al. 2002; Oosterveen et al. 2007). PRY-1 physically interacts with APR-1, GSK-3, and BAR-1 (Korswagen et al. 2002), presumably to phosphorylate BAR-1, which contains eight GSK-3 consensus phosphorylation sites (Eisenmann et al. 1998). Deletion of these sites results in a hyperactive form of the protein that causes Wnt pathway gain-of-function phenotypes when overexpressed (Eisenmann et al. 1998; Gleason et al. 2002, 2006; Korswagen et al. 2002). Therefore, these data suggest that a Wnt/ $\beta$-catenin-dependent pathway similar to that characterized in other species also functions in C. elegans during larval development.

In three different larval developmental processes, WBC pathway activity is necessary to maintain Hox gene expression in Wnt-receiving cells: WBC activity maintains expression of the midbody Hox gene lin-39 during vulval precursor cell-fate specification (Eisenmann et al. 1998; Penigault and Felix 2011b), and is believed to be required for expression of the posterior Hox gene egl-5 during P12 fate specification (Jiang and Sternberg 1998; Eisenmann and Kim 2000; Li et al. 2009) and for expression of the mid/posterior Hox gene mab-5 in the daughters of the QL neuroblast to mediate their proper cell migration (Harris et al. 1996; Maloof et al. 1999; Eisenmann and Kim 2000; Herman 2001; Korswagen et al. 2002). As an example of WBC pathway function in C. elegans, we consider this last process.

\section{CANONICAL WNT SIGNALING REGULATES MIGRATION OF THE QL NEUROBLAST PROGENY}

During the early L1 larval stage, a pair of neuroblasts are born in the posterior in equivalent positions on the left (QL) and on the right (QR) (Sulston and Horvitz 1977). Both cells begin with an anterior migration; however, the three QL neuroblast descendants (QL.d) 
A

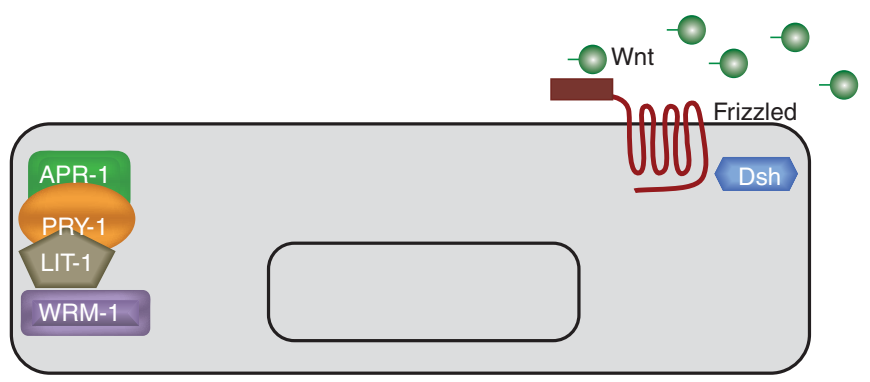

B

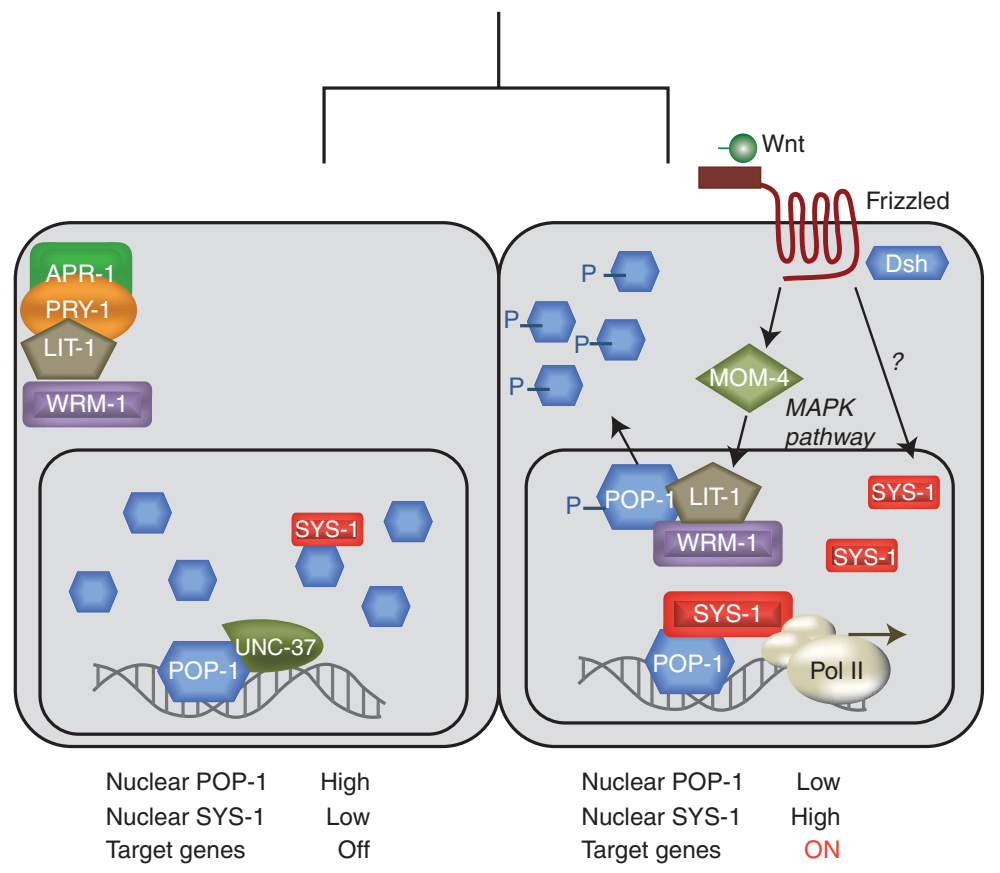

Figure 4. The $C$. elegans Wnt/ $\beta$-catenin asymmetry (WBA) signaling pathway. $(A)$ Asymmetric subcellular localization of Wnt pathway components in a mother cell before cell division. Frizzled and Disheveled proteins localize to the cortex on the side from which the Wnt signal is received, whereas PRY-1/Axin, APR-1/APC, WRM- $1 / \beta$-catenin, and LIT-1/NLK proteins are found on the opposite side. Events in the nucleus are not shown. (B) Asymmetric pathway activation in the two daughters after cell division. In the daughter on the left, the Wnt and MAPK pathways are inactive, nuclear levels of POP-1/TCF are high, while nuclear levels of $\beta$ catenin SYS-1 are low. POP-1/TCF interacts with repressors to keep target gene expression low. In the daughter cell on the right, Wnt ligand activates WBA and MAPK pathways. The $\beta$-catenin WRM- 1 interacts with LIT-1/ NLK to phosphorylate POP-1/TCF, targeting it for nuclear export, thereby lowering the levels of nuclear POP-1. An unknown mechanism leads to an increase in nuclear levels of $\beta$-catenin SYS- 1 in this daughter cell (question mark). POP-1 and SYS-1 interact to up-regulate expression of Wnt target genes (red rectangle). Unlabeled blue hexagons indicate high levels of nuclear POP-1 (left) or phosphorylated, cytoplasmic POP-1 (right).

migrate to the posterior in response to the $\mathrm{Wnt}$ EGL-20 (Herman 2002; Korswagen et al. 2002; Silhankova and Korswagen 2007), which is expressed in a posterior-to-anterior gradient (Coudreuse et al. 2006). Although both the $\mathrm{QL}$ and QR cells are exposed to the ligand, they have different intrinsic sensitivities. In the more sensitive QL neuroblast, exposure to EGL20 leads to $\mathrm{Wnt} / \beta$-catenin pathway activation, expression of the Hox gene mab-5, and posterior migration of progeny, whereas the less sensitive QR neuroblast and its progeny do not 
express $m a b-5$ and continue to migrate toward the anterior (Fig. 3B) (Salser and Kenyon 1992; Whangbo and Kenyon 1999). Loss of function of the positively acting WBC pathway genes mig14/Wntless, vps-35/retromer, egl-20/Wnt, lin$17 / \mathrm{Fz}$, mig-1/Fz, mig-5/Dsh, bar-1/ $\beta$-cat, and pop-1/TCF, or overexpression of the negative regulators $g$ sk-3/GSK $3 \beta$ and $p r y-1 / A x i n$, leads to loss of $m a b-5$ expression and the anterior migration of the QL.d cells (Fig. 3C) (Harris et al. 1996; Maloof et al. 1999; Eisenmann and Kim 2000; Korswagen et al. 2000; Herman 2001; Zinovyeva et al. 2008). Conversely, loss of negative regulation by Axin in a pry-1/axin mutant or pry-1; axl-1 double mutant causes ectopic expression of mab-5 in the QR.d cells, which then migrate to the posterior (Fig. 3D) (Korswagen et al. 2002; Oosterveen et al. 2007).

The products of two genes appear to regulate the levels of EGL-20/Wnt along the anterior-posterior axis and modulate WBC pathway activation in the migrating neuroblast daughters. First, cam-1 encodes a Ror receptor tyrosine kinase, and overexpression of cam-1/Ror reduces mab-5 expression and results in the anterior migration of the QL.d (Kim and Forrester 2003; Forrester et al. 2004). This result is also observed upon overexpression of just the CAM1 extracellular cysteine-rich domain and transmembrane domain, which suggests that CAM-1 may serve as a sink for the EGL-20 signal along the anterior-posterior axis. Second, the $s f r p-1$ gene was recently shown to encode an SFRP family member that is expressed in the anterior (Fig. 2) (Harterink et al. 2011). Loss of sfrp-1 function can suppress the QL.d anterior migration phenotype caused by loss of mig-14/ Wntless (Fig. 3F) but not that caused by loss of mab-5/Hox, whereas overexpression of SFRP-1 leads to the QL.d migrating to even more posterior positions (Fig. 3D). These data suggest that SFRP-1 may regulate the activation of Wnt signaling in these and other cells migrating along the anterior-posterior axis by binding to Wnt proteins expressed from the posterior (EGL-20, LIN-44, and CWN-1) and creating a sharper Wnt gradient along this axis.

Thus, in this process, initial intrinsic differences in sensitivity to Wnt signals between two related cells leads to activation of a canonical $\mathrm{Wnt} / \beta$-catenin-dependent pathway and target gene expression, which controls the final position of migrating cells along an axial Wnt gradient.

\section{THE WNT/ $\beta$-CATENIN ASYMMETRY (WBA) PATHWAY: NEW TRICK}

The Wnt/ $\beta$-catenin asymmetry (WBA) pathway was the first Wnt pathway characterized in C. elegans (Rocheleau et al. 1997; Thorpe et al. 1997), and it is known to regulate many asymmetric cell divisions during C. elegans embryonic and larval development (Fig. 4) (for review, see Eisenmann 2005; Mizumoto and Sawa 2007b; Phillips and Kimble 2009). The WBA pathway uses the diverged $\beta$-catenins SYS-1 and WRM-1, but not BAR-1, suggesting a strong segregation of $\beta$-catenin function between the two $C$. elegans pathways. Interestingly, this pathway may be a nematode-specific variation on the canonical Wnt/TCF-dependent signaling pathway theme.

For some cells whose fate is regulated by the WBA pathway, Frizzled and Disheveled proteins have been found to asymmetrically localize at the cortex of the mother cell on the side at which the Wnt signal is received, whereas negative regulators APC and Axin localize to the opposite side of the mother cell cortex (Park et al. 2004; Walston et al. 2004; Takeshita and Sawa 2005; Goldstein et al. 2006; Mizumoto and Sawa 2007a). Then, upon cell division and the asymmetrical distribution of these cytoplasmic components, Wnt pathway activation occurs in only one of the two daughter cells. Therefore, the hallmark of the WBA pathway is one or more asymmetries between two daughter cells in (1) the localization of upstream pathway components to the cell cortex, (2) the levels of downstream pathway components in the daughter cell nuclei, and (3) the activation of the Wnt signaling pathway (Fig. 4A,B) (Mizumoto and Sawa 2007b; Phillips and Kimble 2009).

In this pathway, Wnt-dependent activation of target genes by TCF and $\beta$-catenin occurs, but proceeds through a novel mechanism distinct from that seen in the $\mathrm{Wnt} / \beta$-catenin canonical 
signaling pathway (Fig. 4B). A major mechanistic difference with the canonical pathway is that in the WBA pathway, target gene activation requires a $\beta$-catenin (WRM-1) and mitogen-activated protein kinase/Nemo-like kinase (MAPK/ NLK)-dependent nuclear export of phosphorylated POP-1/TCF from the nucleus of the cell in which the pathway is active. In this pathway, in addition to activating the Wnt pathway in one daughter, Wnt ligand binding activates the kinases MOM-4/TAK1 and LIT-1/NLK (Rocheleau et al. 1997; Thorpe et al. 1997; Meneghini et al. 1999). The diverged $\beta$-catenin WRM-1 binds to nuclear POP-1/TCF using a carboxy-terminal domain distinct from the canonical amino-terminal $\beta$-catenin-binding domain, and recruits the activated LIT-1/NLK to POP-1/TCF (Korswagen et al. 2000; Natarajan et al. 2001; Yang et al. 2011). The subsequent phosphorylation of POP-1 marks it for nuclear export by PAR-5/14-3-3 and CRM-1/ Exportin (Rocheleau et al. 1997; Meneghini et al. 1999; Shin et al. 1999; Lo et al. 2004), leading to a lowering of POP-1/TCF levels in the nucleus of the signaled cell (Lin et al. 1998; Meneghini et al. 1999; Rocheleau et al. 1999; Herman 2001; Maduro et al. 2002; Park and Priess 2003; Siegfried et al. 2004; Huang et al. 2007; Phillips et al. 2007). Although the mechanism is unclear, in this daughter cell there is also a Wnt-induced increase in the levels of the $\beta$-catenin SYS-1 in the nucleus (Huang et al. 2007; Phillips et al. 2007). The end result of these Wnt-induced events is an asymmetric distribution of TCF and $\beta$-catenin between sister cell nuclei (Fig. 4B).

A decrease in nuclear levels of the pathway transcriptional effector may seem like an unusual outcome for the cell in which the pathway is activated and target genes are expressed. The current model (Phillips and Kimble 2009) suggests that in the nonactivated daughter cell, high POP-1/TCF levels and low SYS- $1 / \beta$-catenin levels result in the formation of transcriptional repressor complexes between POP-1/TCF and corepressors such as UNC-37/Groucho and HDA-1/histone deacetylase, which act to repress target genes that regulate cell fate or behavior (Fig. 4B, left). Conversely, in the Wnt- activated daughter cell, the lower POP-1/TCF levels and higher SYS- $1 / \beta$-catenin levels result in formation of a typical TCF $/ \beta$-catenin bipartite transcription activator, which activates expression of target genes (Fig. 4B, right) (Calvo et al. 2001; Zhao et al. 2002; Maduro et al. 2005; Shetty et al. 2005; Arata et al. 2006; Lam et al. 2006; Huang et al. 2007; Owraghi et al. 2010). Molecular genetic manipulations that artificially alter the ratio of TCF to $\beta$-catenin between daughter cells lead to changes in gene expression or cell fate that are consistent with this model of Wnt pathway activation, switching the transcriptional behavior of TCF in the nucleus (Kidd et al. 2005; Lam et al. 2006; Huang et al. 2007; Bertrand and Hobert 2009).

The WBA pathway may be the major pathway mediating Wnt signals during development in the worm, as it controls numerous asymmetric cell divisions in the embryo, as well as the asymmetric division of the somatic gonad primordia and the stem cell-like divisions of the hypodermal seam cells in the larva (Eisenmann 2005; Mizumoto and Sawa 2007b; Phillips and Kimble 2009). As an example of the use of this pathway, we consider one of the first- and beststudied developmental processes regulated by the WBA pathway, the asymmetric division of the blastomere EMS in the early embryo to generate endodermal and mesodermal precursors.

\section{P2/EMS SIGNALING IN EMBYONIC ENDODERM INDUCTION}

At the four-cell stage in early embryogenesis, the EMS blastomere divides to generate an anterior MS daughter that generates mesodermal tissue and a posterior E daughter that generates all the worm's endoderm (Fig. 5A) (Sulston 1983). Blastomere isolation experiments showed that the posterior blastomere $\mathrm{P} 2$ is required for production of endoderm by EMS, indicating that a signal from P2 polarizes the asymmetric EMS division to generate a daughter with an $\mathrm{E}$ fate (Goldstein 1992, 1993; Goldstein et al. 2006). Forward and reverse genetic screens identified components of Wnt, MAPK, and Src signaling pathways as being required for endoderm formation (Lin et al. 1995; Kaletta et al. 1997; 
B.M. Jackson and D.M. Eisenmann

A Wild type

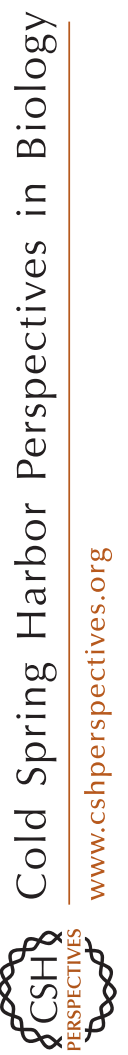
apr-1,

C $p o p-1$

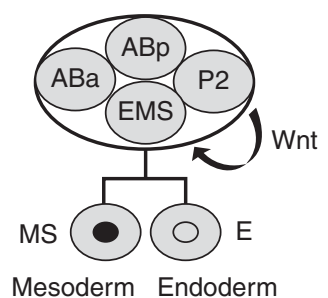

B mig-14, mom-1, mom-2, mom-5 mig-5, dsh-2, kin-19, gsk-3, mom-4, lit-1, wrm-1, sys-1

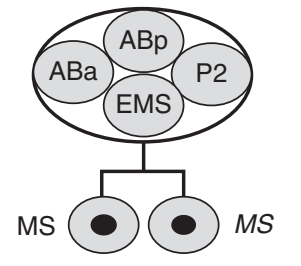

Mesoderm Mesoderm

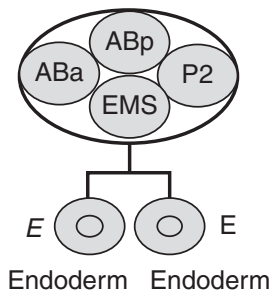

Figure 5. Wnt-dependent endoderm induction at the four-cell stage. (A) At the four-cell stage of embryogenesis, a Wnt signal from the posterior blastomere P2 instructs the EMS blastomere to divide asymmetrically, generating an anterior daughter (MS) that makes mesodermal cells and a posterior daughter (E) that is the endodermal founder cell. Nuclear levels of POP-1/TCF are high in MS (filled circle) and low in $\mathrm{E}$ (open circle). (B) Mutations in components of the WBA and MAPK signaling pathways lead to a symmetric division in which both daughters have high nuclear levels of POP-1/TCF and adopt an MS cell fate, resulting in more mesoderm (Mom phenotype). (C) Loss of POP-1/TCF leads to both daughters adopting the $\mathrm{E}$ cell fate and generating excess endodermal cells. Anterior is to the left, dorsal is up.

Rocheleau et al. 1997, 1999; Meneghini et al. 1999; Peters et al. 1999; Schlesinger et al. 1999; Shin et al. 1999; Bei et al. 2002; Thorpe and Moon 2004; Walston et al. 2004; Huang et al. 2007; Phillips et al. 2007). Wnt pathway components functioning in endoderm induction include MOM-1/Porcupine, MOM-2/Wnt, MIG-14/ Wntless (a.k.a. MOM-3), MOM-5/Fz, DSH-2/ Dsh, MIG-5/Dsh, KIN-19/CK1, GSK-3/GSK3 $\beta$, APR-1/APC, WRM- $1 / \beta$-catenin, SYS- $1 / \beta$-cate- nin, and POP-1/TCF, while the MAPK signaling factors are TAP-1/TabAB1, MOM-4/TAK, and LIT-1/NLK (Meneghini et al. 1999; Rocheleau et al. 1999; Shin et al. 1999). The Tyr kinase receptor MES- 1 and the Src homolog SRC-1 also participate in endoderm induction, but their role is less clear and they are not considered here (Bei et al. 2002; Zhang et al. 2008; Sugioka and Sawa 2010; Sumiyoshi et al. 2011). Mutations or RNAi reduction of function for these Wnt and MAPK pathway genes, with the exception of pop-1/TCF, leads to a Mom phenotype (more mesoderm), in which EMS divides symmetrically to give two MS-like daughters (Fig. 5B). pop-1/TCF mutations cause the opposite phenotype, the generation of two E-like daughters from EMS (Fig. 5C) (Lin et al. 1995). Notice that in this pathway, loss of the GSK3 $\beta, \mathrm{CK} 1 \alpha$, and APC homologs causes the same phenotype as loss of ligand or receptor, indicating they function as positive regulators of this pathway. This initially led to the idea that this pathway was "noncanonical," but as described below, the outcome of WBA pathway activation is still a TCF/ $\beta$-catenin-dependent activation of gene expression, suggesting the pathway represents a nematode variation on the canonical pathway.

Based on the current model of WBA function derived from studies on this and other processes (Fig. 4) (Eisenmann 2005; Mizumoto and Sawa 2007b; Van Hoffelen and Herman 2008; Phillips and Kimble 2009), Wnt signals (MOM-2) received on the posterior side of the EMS blastomere, where it contacts $\mathrm{P} 2$, result in the asymmetric localization of several pathway components to the anterior and posterior cortex of EMS (Fig. 4A). Upon EMS division this asymmetric localization continues, with WRM- $1 / \beta$-catenin and LIT-1/NLK found primarily in the nucleus of the posterior daughter $\mathrm{E}$, but not in the nucleus of the anterior daughter MS (Fig. 4B). In the anterior MS daughter nucleus, levels of POP-1/TCF are high, levels of the $\beta$-catenin SYS- 1 are lower, and POP- $1 /$ TCF acts with transcriptional repressors such as histone deacetylase to silence expression of the endoderm-specific Wnt target genes end-1 and end3 (Calvo et al. 2001; Maduro et al. 2002; Shetty et al.2005; Owraghi et al. 2010). Conversely, in the 
posterior E daughter, the levels of POP-1/TCF are lower and the levels of SYS-1 are high relative to their levels in the MS cell, and together these factors activate expression of the target genes end-1 and end-3, inducing that cell to adopt the endoderm fate (Huang et al. 2007). The asymmetry in POP-1 levels between the daughter nuclei is an easily observed marker for the differential activation of Wnt signaling between the anterior and posterior daughters (Fig. 5A). Consistent with this model, reduced gene expression of the WBA pathway positive regulators leads to both daughter cells having high levels of POP-1 and adopting the nonactivated MS cell fate (Fig. $5 \mathrm{~B})$, whereas manipulations that increase the SYS-1/POP-1 nuclear ratio (e.g., pop-1 RNAi) lead to both daughter cells having low POP-1 levels and adopting the activated cell fate (Fig. 5C).

Thus, in this process the asymmetric distribution of a Wnt signal to a mother cell leads to an asymmetric localization of Wnt pathway components in the cortex of that cell, and the activation of a signaling pathway in only one of the daughters after cell division. Ligand binding results in activation of a MAPK signaling pathway and a variant Wnt signaling pathway in which several core components that act negatively in the canonical pathway appear to act positively to transduce signal. This variant pathway uses two diverged $\beta$-catenins to regulate the formation of a bipartite TCF $/ \beta$-catenin activator protein in one daughter cell nucleus via a directed export of TCF from the signaled cell. Thus it appears that the worm has evolved a variant of the canonical $\mathrm{Wnt} / \beta$-catenin pathway that uses ancient pathway components in novel ways to activate gene expression in response to Wnt ligand.

\section{CONCLUDING REMARKS}

Although a "canonical" Wnt/ $\beta$-catenin pathway exists in $C$. elegans and controls several different types of processes (cell-fate specification, cell migration), a large number of Wnt-regulated developmental events in the worm use the variant Wnt pathway described above to regulate fate specification after asymmetric cell divisions. Although we have uncovered much about the function of these two pathways, a number of interesting questions remain about Wnt signaling in C. elegans.

Biochemical questions: First, as mentioned above, it remains to be determined if Wnt ligand binding in C. elegans uses an LRP5/6/Arrow homolog, as in other species. If it does not, it will show that Wnt signaling can proceed without the necessity of this component, which may have implications for Wnt signaling in other species. Second, it is unclear how $C$. elegans core components like APC and GSK-3 function in a negative manner in the WBC pathway and in some WBA-mediated processes, but appear to function in a positive manner in the P2/EMS signaling pathway (see Mizumoto and Sawa 2007b). Third, the fact that there is a fair amount of functional/genetic redundancy observed in C. elegans for both Wnt and Wnt receptors is interesting. It remains to be determined whether in these cases there are specific Wnt/receptor pairings mediating specific events, or whether there is true biochemical redundancy for these factors and all that matters is the total amount of Wnt ligand received and the number of receptors available to perceive it. In fact, for some WBA-mediated processes, it is unclear whether any Wnt proteins are involved at all (e.g., some early embryonic asymmetric divisions, somatic gonad division, seam cell divisions). For example, in the case of the larval seam cells, which divide in a stem cell-like asymmetric manner (Altun and Hall 2005), combining mutations in multiple Wnt receptors leads to symmetric divisions and defects in seam cell number, whereas animals lacking four or even all five Wnt genes do not display this phenotype (Gleason and Eisenmann 2010; Yamamoto et al. 2011). How the WBA pathway might function in a Wnt-independent but Wnt receptor-dependent manner is an intriguing question for future analysis. Finally, the exact mechanism by which cortical asymmetric localization of pathway components in the mother cell leads to asymmetric pathway activation in the daughters is only beginning to be understood (Mizumoto and Sawa 2007b).

Evolutionary questions: The major question here is whether the variant WBA signaling 
B.M. Jackson and D.M. Eisenmann

pathway exists and is used in other metazoans or whether it was a nematode-specific "invention" during evolution. Although hints of functions like those seen in the WBA pathway have been reported (see Phillips and Kimble 2009), there is currently no strong evidence that this pathway is used in other nonnematode species. This lack of evidence must be tempered by results from C. elegans that show that Wnt pathway components (such as SYS-1 and AXL-1) may lurk in genomes, but be overlooked by purely bioinformatic approaches. A final question is whether C. elegans uses a "noncanonical" $\beta$-cateninindependent Wnt/PCP pathway like that characterized in vertebrates and Drosophila. Although homologs of Wnt/PCP pathway components exist in the $C$. elegans genome, and mutations lead to weak phenotypes in some Wnt-mediated processes ( $\mathrm{Wu}$ and Herman 2006, 2007; King et al. 2009), the evidence for a Wnt/PCP pathway in C. elegans is currently weak.

Therefore, in summary, it is possible that in terms of Wnt signaling, nematodes are "the same, but different" compared with other metazoans. Although still clearly relying on the major metazoan Wnt signaling pathway (WBC), they have also created a novel variant on the Wnt/ $\beta$-catenin pathway (WBA), which mediates a major portion of Wnt signaling in this species.

\section{ACKNOWLEDGMENTS}

We thank members of the Eisenmann laboratory for critical reading of the manuscript, and thank C. elegans colleagues for discussions and sharing of unpublished results. The authors are supported by grants from National Institutes of Health (NIH)/National Institute of General Medical Sciences and National Science Foundation (D.M.E.) and an NIH Ruth L. Kirschstein National Research Service Award (B.M.J.).

\section{REFERENCES}

Altun ZF, Hall DH. 2009. Epithelial system, seam cells. WormAtlas doi: 10.3908/wormatlas.1.14.

Arata Y, Kouike H, Zhang Y, Herman MA, Okano H, Sawa H. 2006. Wnt signaling and a Hox protein cooperatively regulate $p s a-3 / M e i s$ to determine daughter cell fate after asymmetric cell division in C. elegans. Dev Cell 11: 105115.

Arce L, Yokoyama NN, Waterman ML. 2006. Diversity of LEF/TCF action in development and disease. Oncogene 25: 7492-7504.

Atcha FA, Munguia JE, Li TW, Hovanes K, Waterman ML. 2003. A new $\beta$-catenin-dependent activation domain in T cell factor. J Biol Chem 278: 16169-16175.

Atcha FA, Syed A, Wu B, Hoverter NP, Yokoyama NN, Ting JH, Munguia JE, Mangalam HJ, Marsh JL, Waterman ML. 2007. A unique DNA binding domain converts Tcell factors into strong Wnt effectors. Mol Cell Biol 27: $8352-8363$.

Axelrod JD. 2009. Progress and challenges in understanding planar cell polarity signaling. Semin Cell Dev Biol 20: 964-971.

Banziger C, Soldini D, Schutt C, Zipperlen P, Hausmann G, Basler K. 2006. Wntless, a conserved membrane protein dedicated to the secretion of Wnt proteins from signaling cells. Cell 125: 509-522.

Bei Y, Hogan J, Berkowitz LA, Soto M, Rocheleau CE, Pang KM, Collins J, Mello CC. 2002. SRC-1 and Wnt signaling act together to specify endoderm and to control cleavage orientation in early C. elegans embryos. Dev Cell 3: 113-125.

Belenkaya TY, Wu Y, Tang X, Zhou B, Cheng L, Sharma YV, Yan D, Selva EM, Lin X. 2008. The retromer complex influences Wnt secretion by recycling Wntless from endosomes to the trans-Golgi network. Dev Cell 14: 120-131.

Bertrand V, Hobert O. 2009. Linking asymmetric cell division to the terminal differentiation program of postmitotic neurons in C. elegans. Dev Cell 16: 563-575.

Cadigan KM, Peifer M. 2009. Wnt signaling from development to disease: Insights from model systems. Cold Spring Harb Perspect Biol 1: a002881.

Calvo D, Victor M, Gay F, Sui G, Luke MP, Dufourcq P, Wen G, Maduro M, Rothman J, Shi Y. 2001. A POP-1 repressor complex restricts inappropriate cell type-specific gene transcription during Caenorhabditis elegans embryogenesis. EMBO J 20: 7197-7208.

Clevers H. 2006. Wnt/ $\beta$-catenin signaling in development and disease. Cell 127: 469-480.

Costa M, Raich W, Agbunag C, Leung B, Hardin J, Priess JR. 1998. A putative catenin-cadherin system mediates morphogenesis of the Caenorhabditis elegans embryo. J Cell Biol 141: 297-308.

Coudreuse DY, Roel G, Betist MC, Destree O, Korswagen HC. 2006. Wnt gradient formation requires retromer function in Wnt-producing cells. Science 312: 921-924.

Dreier L, Burbea M, Kaplan JM. 2005. LIN-23-mediated degradation of $\beta$-catenin regulates the abundance of GLR-1 glutamate receptors in the ventral nerve cord of C. elegans. Neuron 46: 51-64.

Eisenmann DM. 2005. Wnt signaling. In WormBook: The online review of $\mathrm{C}$. elegans biology (ed. The C. elegans Research Community). WormBook, doi: 10.1895/ wormbook.1.7.1.

Eisenmann DM, Kim SK. 2000. Protruding vulva mutants identify novel loci and Wnt signaling factors that 
function during Caenorhabditis elegans vulva development. Genetics 156: 1097-1116.

Eisenmann DM, Maloof JN, Simske JS, Kenyon C, Kim SK. 1998. The $\beta$-catenin homolog BAR-1 and LET-60 Ras coordinately regulate the Hox gene lin-39 during Caenorhabditis elegans vulval development. Development 125: 3667-3680.

Forrester WC, Kim C, Garriga G. 2004. The Caenorhabditis elegans Ror RTK CAM-1 inhibits EGL-20/Wnt signaling in cell migration. Genetics 168: 1951-1962.

Gleason JE, Eisenmann DM. 2010. Wnt signaling controls the stem cell-like asymmetric division of the epithelial seam cells during C. elegans larval development. Dev Biol 348: 58-66.

Gleason JE, Korswagen HC, Eisenmann DM. 2002. Activation of Wnt signaling bypasses the requirement for RTK/ Ras signaling during C. elegans vulval induction. Genes Dev 16: $1281-1290$.

Gleason JE, Szyleyko EA, Eisenmann DM. 2006. Multiple redundant Wnt signaling components function in two processes during C. elegans vulval development. Dev Biol 298: $442-457$.

Goldstein B. 1992. Induction of gut in Caenorhabditis elegans embryos. Nature 357: 255-257.

Goldstein B. 1993. Establishment of gut fate in the E lineage of C. elegans: The roles of lineage-dependent mechanisms and cell interactions. Development 118: 1267-1277.

Goldstein B, Takeshita H, Mizumoto K, Sawa H. 2006. Wnt signals can function as positional cues in establishing cell polarity. Dev Cell 10: 391-396.

Green JL, Inoue T, Sternberg PW. 2007. The C. elegans ROR receptor tyrosine kinase, CAM-1, non-autonomously inhibits the Wnt pathway. Development 134: 4053-4062.

Green JL, Inoue T, Sternberg PW. 2008. Opposing Wnt pathways orient cell polarity during organogenesis. Cell 134: $646-656$

Guder C, Philipp I, Lengfeld T, Watanabe H, Hobmayer B, Holstein TW. 2006. The Wnt code: Cnidarians signal the way. Oncogene 25: 7450-7460.

Hall DH, Altun ZF. 2008. Epithelial system: Seam cells. In C. elegans atlas, pp. 35-41. Cold Spring Harbor Laboratory Press, Cold Spring Harbor, NY.

Han M. 1997. Gut reaction to Wnt signaling in worms. Cell 90: $581-584$.

Hardin J, King RS. 2008. The long and the short of Wnt signaling in C. elegans. Curr Opin Genet Dev 18: $362-$ 367.

Harris J, Honigberg L, Robinson N, Kenyon C. 1996. Neuronal cell migration in C. elegans: Regulation of Hox gene expression and cell position. Development 122: 31173131.

Harterink M, Kim DH, Middelkoop TC, Doan TD, van Oudenaarden A, Korswagen HC. 2011. Neuroblast migration along the anteroposterior axis of $C$. elegans is controlled by opposing gradients of Wnts and a secreted Frizzled-related protein. Development 138: 2915-2924.

Hatzis P, van der Flier LG, van Driel MA, Guryev V, Nielsen F, Denissov S, Nijman IJ, Koster J, Santo EE, Welboren W, et al. 2008. Genome-wide pattern of TCF7L2/TCF4 chromatin occupancy in colorectal cancer cells. Mol Cell Biol 28: $2732-2744$.
Hayashi Y, Hirotsu T, Iwata R, Kage-Nakadai E, Kunitomo H, Ishihara T, Iino Y, Kubo T. 2009. A trophic role for Wnt-Ror kinase signaling during developmental pruning in Caenorhabditis elegans. Nat Neurosci 12: 981-987.

Herman MA. 2001. C. elegans POP-1/TCF functions in a canonical Wnt pathway that controls cell migration and in a noncanonical Wnt pathway that controls cell polarity. Development 128: 581-590.

Herman MA. 2002. Control of cell polarity by noncanonical Wnt signaling in C. elegans. Semin Cell Dev Biol 13: 233-241.

Herman MA, Vassilieva LL, Horvitz HR, Shaw JE, Herman RK. 1995. The C. elegans gene lin-44, which controls the polarity of certain asymmetric cell divisions, encodes a Wnt protein and acts cell nonautonomously. Cell 83: 101-110.

Hilliard MA, Bargmann CI. 2006. Wnt signals and Frizzled activity orient anterior-posterior axon outgrowth in C. elegans. Dev Cell 10: 379-390.

Howard RM, Sundaram MV. 2002. C. elegans EOR-1/PLZF and EOR-2 positively regulate Ras and Wnt signaling and function redundantly with LIN-25 and the SUR-2 Mediator component. Genes Dev 16: 1815-1827.

Huang S, Shetty P, Robertson SM, Lin R. 2007. Binary cell fate specification during C. elegans embryogenesis driven by reiterated reciprocal asymmetry of TCF POP- 1 and its coactivator $\beta$-catenin SYS-1. Development 134: 2685 2695.

Inoue T, Oz HS, Wiland D, Gharib S, Deshpande R, Hill RJ, Katz WS, Sternberg PW. 2004. C. elegans LIN-18 is a Ryk ortholog and functions in parallel to LIN-17/Frizzled in Wnt signaling. Cell 118: 795-806.

Janssen R, Le Gouar M, Pechmann M, Poulin F, Bolognesi R, Schwager EE, Hopfen C, Colbourne JK, Budd GE, Brown SJ, et al. 2010. Conservation, loss, and redeployment of Wnt ligands in protostomes: Implications for understanding the evolution of segment formation. BMC Evol Biol 10: 374.

Jiang LI, Sternberg PW. 1998. Interactions of EGF, Wnt and HOM-C genes specify the P12 neuroectoblast fate in C. elegans. Development 125: 2337-2347.

Kaletta T, Schnabel H, Schnabel R. 1997. Binary specification of the embryonic lineage in Caenorhabditis elegans. Nature 390: 294-298.

Kennerdell JR, Fetter RD, Bargmann CI. 2009. Wnt-Ror signaling to SIA and SIB neurons directs anterior axon guidance and nerve ring placement in C. elegans. Development 136: 3801-3810.

Kidd AR 3rd, Miskowski JA, Siegfried KR, Sawa H, Kimble J. 2005. A $\beta$-catenin identified by functional rather than sequence criteria and its role in Wnt/MAPK signaling. Cell 121: 761-772.

Kim C, Forrester WC. 2003. Functional analysis of the domains of the C. elegans Ror receptor tyrosine kinase CAM-1. Dev Biol 264: 376-390.

King RS, Maiden SL, Hawkins NC, Kidd AR III, Kimble J, Hardin J, Walston TD. 2009. The N- or C-terminal domains of DSH-2 can activate the C. elegans Wnt $/ \beta$-catenin asymmetry pathway. Dev Biol 328: 234-244. 
B.M. Jackson and D.M. Eisenmann

Korswagen HC, Herman MA, Clevers HC. 2000. Distinct $\beta$ catenins mediate adhesion and signalling functions in C. elegans. Nature 406: 527-532.

Korswagen HC, Coudreuse DY, Betist MC, van de Water S, Zivkovic D, Clevers HC. 2002. The Axin-like protein PRY-1 is a negative regulator of a canonical Wnt pathway in C. elegans. Genes Dev 16: 1291-1302.

Lam N, Chesney MA, Kimble J. 2006. Wnt signaling and CEH-22/tinman/Nkx2.5 specify a stem cell niche in C. elegans. Curr Biol 16: 287-295.

Li X, Kulkarni RP, Hill RJ, Chamberlin HM. 2009. HOM-C genes, Wnt signaling and axial patterning in the C. elegans posterior ventral epidermis. Dev Biol 332: $156-165$.

Lin R, Thompson S, Priess JR. 1995. pop-1 encodes an HMG box protein required for the specification of a mesoderm precursor in early C. elegans embryos. Cell 83: 599-609.

Lin R, Hill RJ, Priess JR. 1998. POP-1 and anterior-posterior fate decisions in C. elegans embryos. Cell 92: 229 239.

Lin KT, Broitman-Maduro G, Hung WW, Cervantes S, Maduro MF. 2009. Knockdown of SKN-1 and the Wnt effector TCF/POP-1 reveals differences in endomesoderm specification in C. briggsae as compared with C. elegans. Dev Biol 325: 296-306.

Liu J, Phillips BT, Amaya MF, Kimble J, Xu W. 2008. The C. elegans SYS- 1 protein is a bona fide $\beta$-catenin. Dev Cell 14: $751-761$.

Lo MC, Gay F, Odom R, Shi Y, Lin R. 2004. Phosphorylation by the $\beta$-catenin/MAPK complex promotes 14-3-3-mediated nuclear export of TCF/POP-1 in signal-responsive cells in C. elegans. Cell 117: 95-106.

Love JJ, Li X, Case DA, Giese K, Grosschedl R, Wright PE. 1995. Structural basis for DNA bending by the architec tural transcription factor LEF-1. Nature 376: 791-795.

MacDonald BT, Tamai K, He X. 2009. Wnt/ $\beta$-catenin signaling: Components, mechanisms, and diseases. Dev Cell 17: 9-26.

Maduro MF, Lin R, Rothman JH. 2002. Dynamics of a developmental switch: Recursive intracellular and intranuclear redistribution of Caenorhabditis elegans POP-1 parallels Wnt-inhibited transcriptional repression. Dev Biol 248: $128-142$.

Maduro MF, Kasmir JJ, Zhu J, Rothman JH. 2005. The Wnt effector POP-1 and the PAL-1/Caudal homeoprotein collaborate with SKN-1 to activate C. elegans endoderm development. Dev Biol 285: 510-523.

Maloof JN, Whangbo J, Harris JM, Jongeward GD, Kenyon C. 1999. A Wnt signaling pathway controls Hox gene expression and neuroblast migration in C. elegans. Development 126: 37-49.

Martin BL, Kimelman D. 2009. Wnt signaling and the evolution of embryonic posterior development. Curr Biol 19: R215-R219.

Meneghini MD, Ishitani T, Carter JC, Hisamoto N, Ninomiya-Tsuji J, Thorpe CJ, Hamill DR, Matsumoto K, Bowerman B. 1999. MAP kinase and Wnt pathways converge to downregulate an HMG-domain repressor in Caenorhabditis elegans. Nature 399: 793-797.

Mizumoto K, Sawa H. 2007a. Cortical $\beta$-catenin and APC regulate asymmetric nuclear $\beta$-catenin localization dur- ing asymmetric cell division in C. elegans. Dev Cell 12: 287-299.

Mizumoto K, Sawa H. 2007b. Two $\beta$ s or not two $\beta$ s: Regulation of asymmetric division by $\beta$-catenin. Trends Cell Biol 17: 465-473.

Natarajan L, Witwer NE, Eisenmann DM. 2001. The divergent Caenorhabditis elegans $\beta$-catenin proteins BAR-1, WRM-1 and HMP-2 make distinct protein interactions but retain functional redundancy in vivo. Genetics 159: $159-172$.

Niehrs C. 2010. On growth and form: A Cartesian coordinate system of Wnt and BMP signaling specifies bilaterian body axes. Development 137: 845-857.

Nishiwaki K. 1999. Mutations affecting symmetrical migration of distal tip cells in Caenorhabditis elegans. Genetics 152: 985-997.

Oosterveen T, Coudreuse DY, Yang PT, Fraser E, Bergsma J, Dale TC, Korswagen HC. 2007. Two functionally distinct Axin-like proteins regulate canonical Wnt signaling in C. elegans. Dev Biol 308: 438-448.

Owraghi M, Broitman-Maduro G, Luu T, Roberson H, Maduro MF. 2010. Roles of the Wnt effector POP-1/TCF in the $C$. elegans endomesoderm specification gene network. Dev Biol 340: 209-221.

Pan CL, Howell JE, Clark SG, Hilliard M, Cordes S, Bargmann CI, Garriga G. 2006. Multiple Wnts and Frizzled receptors regulate anteriorly directed cell and growth cone migrations in Caenorhabditis elegans. Dev Cell 10: 367-377.

Pan CL, Baum PD, Gu M, Jorgensen EM, Clark SG, Garriga G. 2008. C. elegans AP-2 and retromer control Wnt signaling by regulating mig-14/Wntless. Dev Cell 14: $132-139$.

Pang K, Ryan JF, Mullikin JC, Baxevanis AD, Martindale MQ. 2010. Genomic insights into Wnt signaling in an early diverging metazoan, the ctenophore Mnemiopsis leidyi. EvoDevo 1: 10.

Park FD, Priess JR. 2003. Establishment of POP-1 asymmetry in early C. elegans embryos. Development 130: 3547-3556.

Park FD, Tenlen JR, Priess JR. 2004. C. elegans MOM-5/ Frizzled functions in MOM-2/Wnt-independent cell polarity and is localized asymmetrically prior to cell division. Curr Biol 14: 2252-2258.

Penigault JB, Felix MA. 2011a. Evolution of a system sensitive to stochastic noise: P3.p cell fate in Caenorhabditis. Dev Biol 357: 419-427.

Penigault JB, Felix MA. 2011b. High sensitivity of C. elegans vulval precursor cells to the dose of posterior Wnts. Dev Biol 357: 428-438.

Peters JM, McKay RM, McKay JP, Graff JM. 1999. Casein kinase I transduces Wnt signals. Nature 401: 345-350.

Petersen CP, Reddien PW. 2009. Wnt signaling and the polarity of the primary body axis. Cell 139: 1056-1068.

Phillips BT, Kimble J. 2009. A new look at TCF and $\beta$-catenin through the lens of a divergent $C$. elegans Wnt pathway. Dev Cell 17: 27-34.

Phillips BT, Kidd AR III, King R, Hardin J, Kimble J. 2007. Reciprocal asymmetry of SYS- $1 / \beta$-catenin and POP- 1 / TCF controls asymmetric divisions in Caenorhabditis elegans. Proc Natl Acad Sci 104: 3231-3236. 
Prasad BC, Clark SG. 2006. Wnt signaling establishes anteroposterior neuronal polarity and requires retromer in C. elegans. Development 133: 1757-1766.

Putzke AP, Rothman JH. 2010. Repression of Wnt signaling by a Fer-type nonreceptor tyrosine kinase. Proc Natl Acad Sci 107: 16154-16159.

Rocheleau CE, Downs WD, Lin R, Wittmann C, Bei Y, Cha YH, Ali M, Priess JR, Mello CC. 1997. Wnt signaling and an APC-related gene specify endoderm in early C. elegans embryos. Cell 90: 707-716.

Rocheleau CE, Yasuda J, Shin TH, Lin R, Sawa H, Okano H, Priess JR, Davis RJ, Mello CC. 1999. WRM-1 activates the LIT-1 protein kinase to transduce anterior/posterior polarity signals in C. elegans. Cell 97: 717-726.

Rudel D, Tian H, Sommer RJ. 2008. Wnt signaling in Pristionchus pacificus gonadal arm extension and the evolution of organ shape. Proc Natl Acad Sci 105: 1082610831.

Ruvkun G, Hobert O. 1998. The taxonomy of developmental control in Caenorhabditis elegans. Science 282: 2033 2041.

Ryan JF, Baxevanis AD. 2007. Hox, Wnt, and the evolution of the primary body axis: Insights from the early-divergent phyla. Biol. Direct 2: 37.

Salser SJ, Kenyon C. 1992. Activation of a C. elegans Antennapedia homologue in migrating cells controls their direction of migration. Nature 355: 255-258.

Sawa H, Lobel L, Horvitz H. 1996. The Caenorhabditis elegans gene lin-17, which is required for certain asymmetric cell divisions, encodes a putative seven-transmembrane protein similar to the Drosophila Frizzled protein. Genes Dev 10: 2189-2197.

Schlesinger A, Shelton CA, Maloof JN, Meneghini M, Bowerman B. 1999. Wnt pathway components orient a mitotic spindle in the early Caenorhabditis elegans embryo without requiring gene transcription in the responding cell. Genes Dev 13: 2028-2038.

Seetharaman A, Cumbo P, Bojanala N, Gupta BP. 2010. Conserved mechanism of Wnt signaling function in the specification of vulval precursor fates in C. elegans and C. briggsae. Dev Biol 346: 128-139.

Shackleford GM, Shivakumar S, Shiue L, Mason J, Kenyon C, Varmus HE. 1993. Two wnt genes in Caenorhabditis elegans. Oncogene 8: 1857-1864.

Shetty P, Lo MC, Robertson SM, Lin R. 2005. C. elegans TCF protein, POP-1, converts from repressor to activator as a result of Wnt-induced lowering of nuclear levels. Dev Biol 285: $584-592$.

Shin TH, Yasuda J, Rocheleau CE, Lin R, Soto M, Bei Y, Davis RJ, Mello CC. 1999. MOM-4, a MAP kinase kinase kinase-related protein, activates WRM-1/LIT-1 kinase to transduce anterior/posterior polarity signals in $C$. elegans. Mol Cell 4: 275-280.

Siegfried KR, Kidd AR III, Chesney MA, Kimble J. 2004. The sys- 1 and sys-3 genes cooperate with Wnt signaling to establish the proximal-distal axis of the Caenorhabditis elegans gonad. Genetics 166: 171-186.

Silhankova M, Korswagen HC. 2007. Migration of neuronal cells along the anterior-posterior body axis of C. elegans: Wnts are in control. Curr Opin Genet Dev 17: 320-325.
Song S, Zhang B, Sun H, Li X, Xiang Y, Liu Z, Huang X, Ding M. 2010. AWnt-Frz/Ror-Dsh pathway regulates neurite outgrowth in Caenorhabditis elegans. PLoS Genet 6: e1001056.

Streit A, Kohler R, Marty T, Belfiore M, Takacs-Vellai K, Vigano MA, Schnabel R, Affolter M, Muller F. 2002. Conserved regulation of the Caenorhabditis elegans labial/ Hoxl gene ceh-13. Dev Biol 242: 96-108.

Sugioka K, Sawa H. 2010. Regulation of asymmetric positioning of nuclei by Wnt and Src signaling and its roles in POP-1/TCF nuclear asymmetry in Caenorhabditis elegans. Genes Cells 15: 397-407.

Sulston JE. 1983. Neuronal cell lineages in the nematode Caenorhabditis elegans. Cold Spring Harb Symp Quant Biol 48 (Pt 2): 443-452.

Sulston J, Horvitz H. 1977. Post-embryonic cell lineages of the nematode, Caenorhabditis elegans. Dev Biol 56: 110156.

Sumiyoshi E, Takahashi S, Obata H, Sugimoto A, Kohara Y. 2011. The $\beta$-catenin HMP-2 functions downstream of Src in parallel with the Wnt pathway in early embryogenesis of C. elegans. Dev Biol 355: 302-312.

Takeshita H, Sawa H. 2005. Asymmetric cortical and nuclear localizations of WRM- $1 / \beta$-catenin during asymmetric cell division in C. elegans. Genes Dev 19: 1743-1748.

Thorpe CJ, Moon RT. 2004. nemo-like kinase is an essential co-activator of Wnt signaling during early zebrafish development. Development 131: 2899-2909.

Thorpe CJ, Schlesinger A, Carter JC, Bowerman B. 1997. Wnt signaling polarizes an early C. elegans blastomere to distinguish endoderm from mesoderm. Cell 90: 695705.

Tian H, Schlager B, Xiao H, Sommer RJ. 2008. Wnt signaling induces vulva development in the nematode Pristionchus pacificus. Curr Biol 18: 142-146.

van Amerongen R, Nusse R. 2009. Towards an integrated view of Wnt signaling in development. Development 136: 3205-3214.

Van Hoffelen S, Herman MA. 2008. Analysis of Wnt signaling during Caenorhabditis elegans postembryonic development. Methods Mol Biol 469: 87-102.

Walston T, Tuskey C, Edgar L, Hawkins N, Ellis G, Bowerman B, Wood W, Hardin J. 2004. Multiple Wnt signaling pathways converge to orient the mitotic spindle in early C. elegans embryos. Dev Cell 7: 831-841.

Wang X, Sommer RJ. 2011. Antagonism of LIN-17/Frizzled and LIN-18/Ryk in nematode vulva induction reveals evolutionary alterations in core developmental pathways. PLoS Biol 9: e1001110.

Whangbo J, Kenyon C. 1999. A Wnt signaling system that specifies two patterns of cell migration in C. elegans. Mol Cell 4: 851-858.

Wu M, Herman MA. 2006. A novel noncanonical Wnt pathway is involved in the regulation of the asymmetric B cell division in C. elegans. Dev Biol 293: 316-329.

Wu M, Herman MA. 2007. Asymmetric localizations of LIN-17/Fz and MIG-5/Dsh are involved in the asymmetric B cell division in C. elegans. Dev Biol 303: 650662. 
B.M. Jackson and D.M. Eisenmann

Yamamoto Y, Takeshita H, Sawa H. 2011. Multiple Wnts redundantly control polarity orientation in Caenorhabditis elegans epithelial stem cells. PLoS Genet 7: e1002308.

Yang PT, Lorenowicz MJ, Silhankova M, Coudreuse DY, Betist MC, Korswagen HC. 2008. Wnt signaling requires retromer-dependent recycling of $\mathrm{MIG}-14 /$ Wntless in Wnt-producing cells. Dev Cell 14: 140-147.

Yang XD, Huang S, Lo MC, Mizumoto K, Sawa H, Xu W, Robertson S, Lin R. 2011. Distinct and mutually inhibitory binding by two divergent $\beta$-catenins coordinates TCF levels and activity in C. elegans. Development 138: 4255-4265.

Zhang H, Skop AR, White JG. 2008. Src and Wnt signaling regulate dynactin accumulation to the P2-EMS cell border in C. elegans embryos. J Cell Sci 121: 155-161.

Zhao X, Yang Y, Fitch DH, Herman MA. 2002. TLP-1 is an asymmetric cell fate determinant that responds to Wnt signals and controls male tail tip morphogenesis in C. elegans. Development 129: 1497-1508.

Zhao X, Sawa H, Herman MA. 2003. tcl-2 encodes a novel protein that acts synergistically with Wnt signaling pathways in C. elegans. Dev Biol 256: 276-289.

Zheng M, Messerschmidt D, Jungblut B, Sommer RJ. 2005. Conservation and diversification of Wnt signaling function during the evolution of nematode vulva development. Nat Genet 37: 300-304.

Zinovyeva AY, Forrester WC. 2005. The C. elegans Frizzled CFZ-2 is required for cell migration and interacts with multiple Wnt signaling pathways. Dev Biol 285: 447461.

Zinovyeva AY, Yamamoto Y, Sawa H, Forrester WC. 2008. Complex network of Wnt signaling regulates neuronal migrations during Caenorhabditis elegans development. Genetics 179: 1357-1371. 


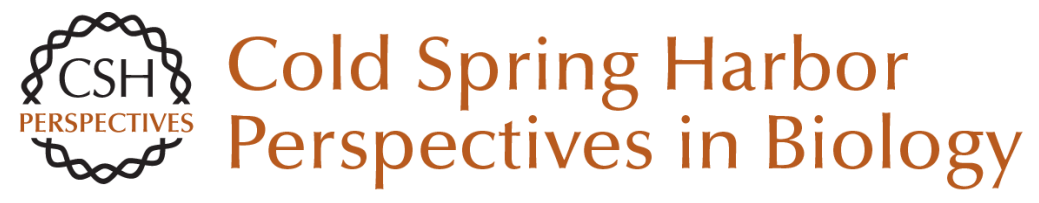

\title{
$\beta$-Catenin-Dependent Wnt Signaling in C. elegans: Teaching an Old Dog a New Trick
}

\author{
Belinda M. Jackson and David M. Eisenmann
}

Cold Spring Harb Perspect Biol 2012; doi: 10.1101/cshperspect.a007948 originally published online June 27, 2012

\section{Subject Collection Wnt Signaling}

Wnt Signaling in Vertebrate Axis Specification Hiroki Hikasa and Sergei Y. Sokol

Secreted and Transmembrane Wnt Inhibitors and Activators Cristina-Maria Cruciat and Christof Niehrs

Wnt Signaling in Normal and Malignant Hematopoiesis

William Lento, Kendra Congdon, Carlijn Voermans, et al.

Frizzled and LRP5/6 Receptors for Wnt/ $/$-Catenin

Signaling

Bryan T. MacDonald and Xi He

TCF/LEFs and Wnt Signaling in the Nucleus

Ken M. Cadigan and Marian L. Waterman

\section{Alternative Wnt Pathways and Receptors} Renée van Amerongen

$\beta$-Catenin-Dependent Wnt Signaling in C. elegans:

Teaching an Old Dog a New Trick Belinda M. Jackson and David M. Eisenmann

The Evolution of the Wnt Pathway Thomas W. Holstein
The $\beta$-Catenin Destruction Complex

Jennifer L. Stamos and William I. Weis

Wnt Signaling in Skin Development, Homeostasis, and Disease Xinhong Lim and Roel Nusse

Wnt Signaling in Bone Development and Disease:

Making Stronger Bone with Wnts Jean B. Regard, Zhendong Zhong, Bart O. Williams, et al.

Targeting Wnt Pathways in Disease Zachary F. Zimmerman, Randall T. Moon and Andy J. Chien

Wnt Signaling in Mammary Glands: Plastic Cell

Fates and Combinatorial Signaling Caroline M. Alexander, Shruti Goel, Saja A. Fakhraldeen, et al.

Wnt Signaling and Injury Repair Jemima L. Whyte, Andrew A. Smith and Jill A. Helms

Wnt Signaling and Forebrain Development Susan J. Harrison-Uy and Samuel J. Pleasure

Wnt Signaling in Neuromuscular Junction Development Kate Koles and Vivian Budnik

For additional articles in this collection, see http://cshperspectives.cshlp.org/cgi/collection/

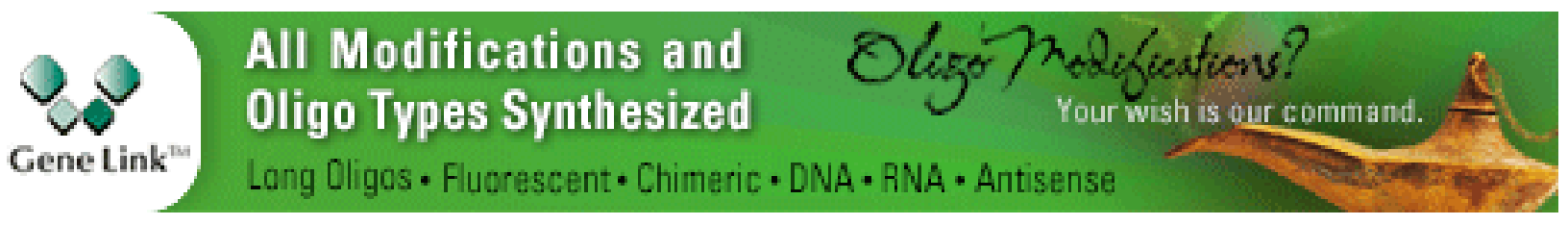

